\title{
Update of endoscopic management of Crohn's disease strictures
}

\author{
Akshay Pokala, Bo Shen \\ Interventional IBD Center, Columbia University Irving Medical Center-New York Presbyterian Hospital, New York, NY, USA
}

One of the most common complications of Crohn's disease (CD) is the formation of strictures. Endoscopy plays a vital role not only in the diagnosis, differential diagnosis, and disease monitoring of $\mathrm{CD}$, but also the delivery of effective treatment. The purpose of this review is to update the endoscopic management of strictures in CD. Endoscopic therapy has provided minimally invasive treatment for CD. Commonly used endoscopic treatment modalities include balloon dilation, endoscopic stricturotomy, endoscopic strictureplasty, and endoscopic stenting. The pros and cons of these endoscopic treatment modalities are discussed. (Intest Res 2020;18:1-10)

Key Words: Crohn disease; Endoscopy; Therapy

\section{INTRODUCTION}

Crohn's disease (CD) is a primary form of chronic IBD, mainly affecting the distal ileum and colon. The etiology and pathogenesis of $\mathrm{CD}$ are multifactorial. CD is known to progress from inflammatory phenotype to stricturing or penetrating disease entity, due to the transmural disease process. A majority of $\mathrm{CD}$ patients will develop some forms of complications such as strictures, fistulas, abscess, or colitis-associated neoplasia. Medical therapy for inflammatory strictures of $\mathrm{CD}$ is being explored, while the role of medical therapy in fibrostenotic strictures is limited. Therefore, a majority of patients with CD eventually would need surgery with bowel resection or strictureplasty. The surgical treatment in most patients is not definitive, as postoperative disease recurrence is common. Besides, patients with $\mathrm{CD}$ undergoing surgery are at risk for the development of postoperative complications including anas-

Received November 28, 2019. Revised December 23, 2019.

Accepted December 24, 2019.

Correspondence to Bo Shen, Columbia University Irving Medical Center-

New York Presbyterian Hospital, 161 Ft. Washington Ave, Suite 838 A,

Herbert Irving Pavilion, New York, NY 10032, USA. Tel: +1-212-305-5664,

Fax: +1-212-305-0267, E-mail: bs3720@cumc.columbia.edu tomotic strictures and leaks, short bowel syndrome.

Endoscopic management has emerged as a valid treatment option for CD-related fibrotic strictures. Endoscopic therapy is a middle ground between medical and surgical therapy, which delivers a more effective modality than medical therapy while being less invasive than surgery. Currently available forms of endoscopic management for CD strictures are endoscopic balloon dilation (EBD), endoscopic stricturotomy (ESt) and endoscopic strictureplasty (ESTx), and endoscopic stenting (ES). Outcomes of endoscopic therapy are measured by immediate technical success (i.e., passage of the scope through the stricture), long-term success (e.g., retreatmentfree survival and surgery-free survival), and adverse events (i.e., procedure-associated with bleeding and perforation).

\section{PREPROCEDURAL EVALUATION OF CD STRICTURES}

CD can progress to the luminal narrowing of the bowel with the formation of strictures. In addition, CD patients are prone to recurrent strictures after endoscopic or surgical therapy. Besides, persistent strictures may cause prestenotic dilation and development of fistula at the bowel proximal to the stric- 
ture. There are 2 types of strictures: the primary (or disease-related) strictures and secondary strictures (such as anastomotic stricture and NSAID-associated stricture). Symptoms of strictures include nausea, bloating, vomiting, constipation, and pain or cramps.

Endoscopic therapy has emerged into a main treatment modality for CD strictures. It is imperative that preprocedural cross-sectional imaging of the abdomen and pelvis with CT enterography or MRI. The cross-sectional imaging provides a roadmap for the subsequent endoscopic therapy, delineating the number, length, degree, and location of strictures and the presence of associated prestenotic dilation, abscesses, and fistulas.1 The presence of prestenotic dilation is considered as a feature for the distinction between inflammatory and fibrotic strictures. Endoscopic therapy should be postponed or avoid- ed in patients on systemic corticosteroids with a daily dose $>20 \mathrm{mg}$ to reduce the risk for procedure-associated bleeding or bowel perforation.

\section{ENDOSCOPIC BALLOON DILATION}

EBD of CD or non-CD strictures has been a routine clinical practice. The procedure can be performed in experienced hands, with a majority of EBD procedures be performed in an outpatient setting. Repeated therapy is often required.

\section{Techniques}

Balloon dilation is the first endoscopic treatment modality for CD strictures described in the literature. EBD is performed in an antegrade or retrograde fashion. Antegrade dilation is con-
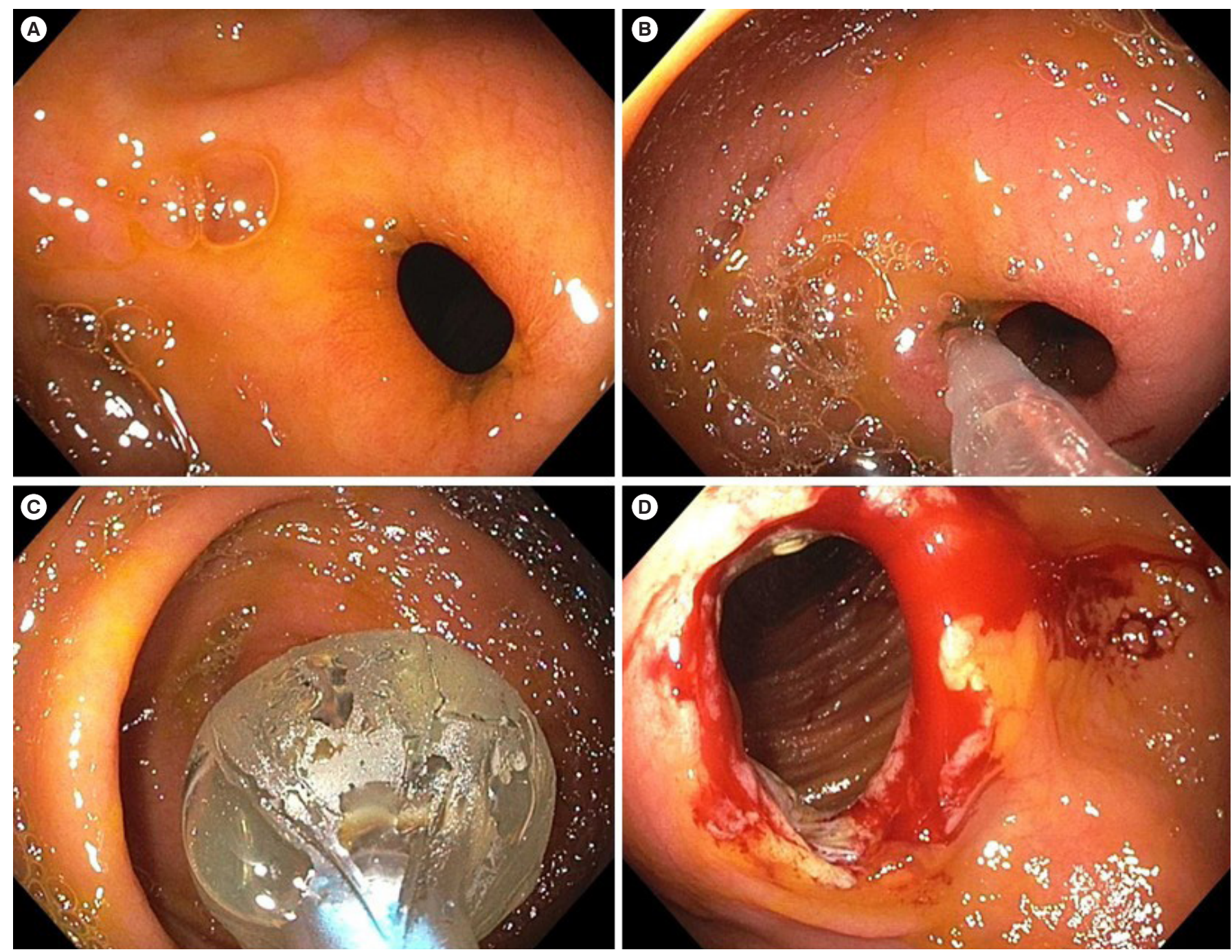

Fig. 1. Antegrade endoscopic balloon dilation of an ileocolonic anastomosis stricture in CD. (A) The tight, nonulcerated stricture at the anastomosis. $(B, C)$ Balloon dilation of the stricture prior to the passage of the scope. (D) Post-dilation appearance of the stricture with some bleeding. 
ducted for the treatment non-traversable stricture, with the endoscopist blindly pushing the balloon sheath through the stricture (Fig. 1). However, retrograde EBD is preferred, as the technique involves passage of the scope through the stricture, feeding of the balloon sheath, pulling back of the balloon sheath along with the scope, and insufflation of the balloon (Fig. 2). Other EBD techniques include wire-exchange, wire-out, and direct-view during balloon insufflation. EBD is performed with the balloon being insufflated to different diameters with the target the size of balloon being $18-20 \mathrm{~mm}$. The target of EBD treatment is that the passage of the endoscope through the bowel without significant intransigence after the therapy. Repeat dilations may be needed to achieve the target size.

Intralesional injection of long-acting corticosteroids during the dilation to enhance the efficacy has been evaluated with conflict results. There have been 2 randomized controlled trials detailing the use of the injection of corticosteroids into strictures after dilations. However, these trials provided conflicting outcomes. ${ }^{1,2}$ The injection of corticosteroids into a stricture after EBD in pediatric CD reduced the need for redilation and surgery. ${ }^{3}$ However, intra-stricture triamcinolone injection after EBD in adult CD strictures yielded a worse outcome. ${ }^{4}$ In authors' clinical practice, intralesional injection has not been part of routine care. As such, the routine use of intralesional corticosteroids after EBD is not recommended.

\section{Efficacy of EBD in Case Series}

EBD is performed to treat primary and anastomotic strictures in the esophagus, stomach, the proximal or distal small bowel, colon, or anorectum. EBD can also be performed for the treat-
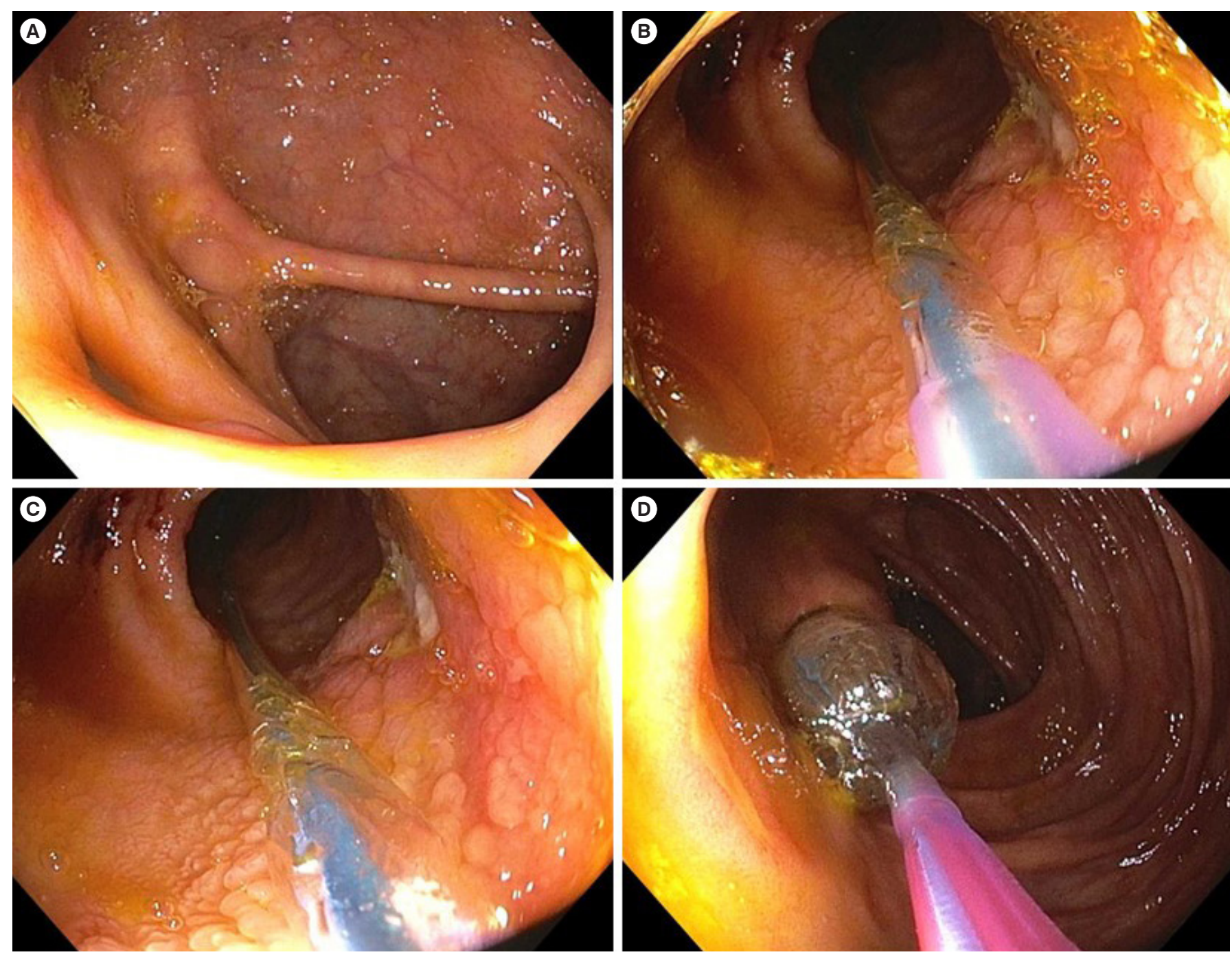

Fig. 2. Retrograde endoscopic balloon dilation of an ileocecal valve stricture in $C D$. (A) The nonulcerated stricture at the ileocecal valve which was traversable to a pediatric colonoscope. (B, C) Passage of endoscope through the stricture and advancement of balloon sheath. (D) Withdrawal of the scope along with advanced balloon sheath and subsequent insufflation of the balloon. 
ment of strictures in surgically altered bowel, such as ileostomy, strictureplasty, and ileal pouch. For non-complex strictures, short strictures that are less than $4-5 \mathrm{~cm}$, single strictures, or strictures without prestenotic dilation, EBD is considered as the first-line therapy. Multiple small and large case series have shown the effectiveness of EBD in patients with CD-related strictures. In the Scimeca et al., 37 patients underwent a total of 72 balloon dilations of strictures for with a mean stricture length of $3.4 \mathrm{~cm}$, which is in the ideal range to perform EBD. The success rate of the first dilation for this study was $51 \%$, and the rate of subsequent procedures was $89 \%$. There were no major complications. A study of 178 patients with 776 dilations by Gustavsson et al., ${ }^{6}$ showed the initial success rate of EBD was 89\%. The long-term success rate of EBD dropped to $52 \%$ and the rate for major complications was $5.3 \%$ including bowel perforation, bleeding, and abdominal pain or fever. A separate study of 55 patients with 93 dilations by Mueller et al., ${ }^{7}$ achieved the initial success rate of $95 \%$ and the long-term success rate of $76 \%$. In a separate study of 135 patients with primary strictures, 66 patients (35.7\%) undergoing EBD later needed salvage surgery. ${ }^{4}$ Lee et al., ${ }^{8}$ followed CD patients who underwent EBD for a median follow-up of 134.8 months, $26.7 \%$ of patients required redilation. In another study, ${ }^{4}$ including 286 CD patients managed with EBD, the cumulative probability of the need for a second dilation following the index procedure was $33.6 \%$ at 1 year (95\% CI, 25.9\%-38.7\%), $53.9 \%$ at 3 years ( $95 \% \mathrm{CI}, 45.9 \%-61.2 \%$ ), and $60.2 \%$ at 5 years (95\% CI, 51.4\%-67.5\%).

Endoscopic therapy may not prevent all patients from having surgery. The reported rate of salvage surgical intervention after EBD ranged from $28 \%$ to $52 \%$ depending on the techniques, settings, and duration of follow-up. ${ }^{3,9-12}$ Several metanalyses confirm the efficacy and safety of EBD in the treatment of CD strictures. ${ }^{4,13,14}$ A systematic review and analysis of data sets of 676 patients also showed that EBD has a high rate of short and long-term efficacy with acceptable rates of complication. In this study, a stricture length of less than $5 \mathrm{~cm}$ was favorably associated with a surgery-free survival. ${ }^{15}$ Bettenworth et al. ${ }^{15}$ in a pooled analysis reported outcomes for 1,463 patients who underwent 3,213 EBD procedures. After 24 months of follow-up, $73.5 \%$ of patients underwent redilation and $42.9 \%$ of patients required surgical resection.

\section{Comparison of Efficacy between EBD and Surgical Resection}

Our group has performed a series of studies in comparison between endoscopic and surgical therapies in CD patients with primary or anastomotic strictures. Lian et al. ${ }^{9}$ evaluated outcomes following EBD versus surgery for ileocolonic anastomosis stricture with patients following ileocolonic resection. We found that surgical resection of ileocolonic anastomotic strictures carried a lower risk of subsequent surgery than EBD. However, EBD spaced out the need for surgery for a significant period time. The average time for surgery was delayed by 6.45 years with EBD as initial treatment. For EBD, the total number of dilations was 447 with a median of 2 (interquartile range [IQR], 1-14) per patient in the endoscopy group. During a median follow-up of 1.8 years (IQR, 0.4-4.1 years), 91 patients $(51.7 \%)$ required subsequent surgery for stricture. The technical failure rate of EBD was 9.7\% (17/176 patients). The median follow-up was 1.76 years (IQR, $0.38-4.125$ years) for the EBD group and 4.7 years (IQR, 2.2-8.8 years) for the surgery group. Subsequently, Lan et al. ${ }^{16}$ reported lower rates of efficacy and adverse events of patients with primary ileocolonic strictures treated by EBD than those treated with surgical resection. A total of $44.4 \%$ of patients treated with EBD required salvage surgery as compared with $21.7 \%$ of patients treated with ileocolonic resection, resulting in a difference in surgery-free survival $(11.1 \pm 0.6$ years vs. $5.4 \pm 0.6$ years, $P<$ 0.001 ). However, the frequency of adverse events in the EBD group is significantly lower than that in the surgery group ( $4.7 \%$ vs. $32.2 \%, P<0.0001$ ). It appears that EBD is more effective in the treatment of the anastomotic strictures than the primary strictures, although an earlier study from our group showed no statistical difference between 2 types of strictures. The possible explanation is that the latter study also included the primary or anastomotic strictures in the upper GI tract, neo-ileum strictures with stomas, and ileal pouches. ${ }^{3}$

There are no published data on the comparison of the outcomes between EBD and surgical strictureplasty in the treatment of CD strictures.

Table 1. Comparison of Efficacy and Complications in Endoscopic and Surgical Management of CD Strictures

\begin{tabular}{|c|c|c|c|c|}
\hline & \multicolumn{2}{|c|}{ Endoscopy (\%) } & \multicolumn{2}{|c|}{ Surgery (\%) } \\
\hline & $\begin{array}{l}\text { Balloon } \\
\text { dilation }\end{array}$ & $\begin{array}{l}\text { Stricturotomy or } \\
\text { strictureplasty }\end{array}$ & $\begin{array}{l}\text { Resection and } \\
\text { anastomosis }\end{array}$ & Strictureplasty \\
\hline Efficacy & ++ & +++ & +++ & +++ \\
\hline Bleeding & $2-3$ & $6-10$ & $\begin{array}{l}\text { All complications } \\
20-40\end{array}$ & $\begin{array}{c}\text { All complications } \\
20-30\end{array}$ \\
\hline Perforation & $1-5$ & 1 & & \\
\hline
\end{tabular}




\section{Adverse Events Associated with EBD}

EBD is generally considered a safe treatment modality. The main safety concerns have been procedure-associated bleeding and perforation. There was $1 \%$ complication rate for every procedure; however, there is an $8 \%$ complication rate per procedure for surgical related treatments of ileocolonic anastomosis strictures in $\mathrm{CD}^{10}$ In addition, approximately $2 \%-3 \%$ of patients undergoing EBD had bleeding and 6\%-10\% having stricturotomy or strictureplasty developed late-onset bleeding (Table 1). In contrast, surgical resection of the stricture is associated with $20 \%-40 \%$ complication rates. There were $1 \%-5 \%$ and $1 \%$ of the risk of perforation for EBD or ESt/strictureplasty, respectively. There is a likelihood of multiple dilations in order to treat long-term stricture reoccurrences. ${ }^{17}$
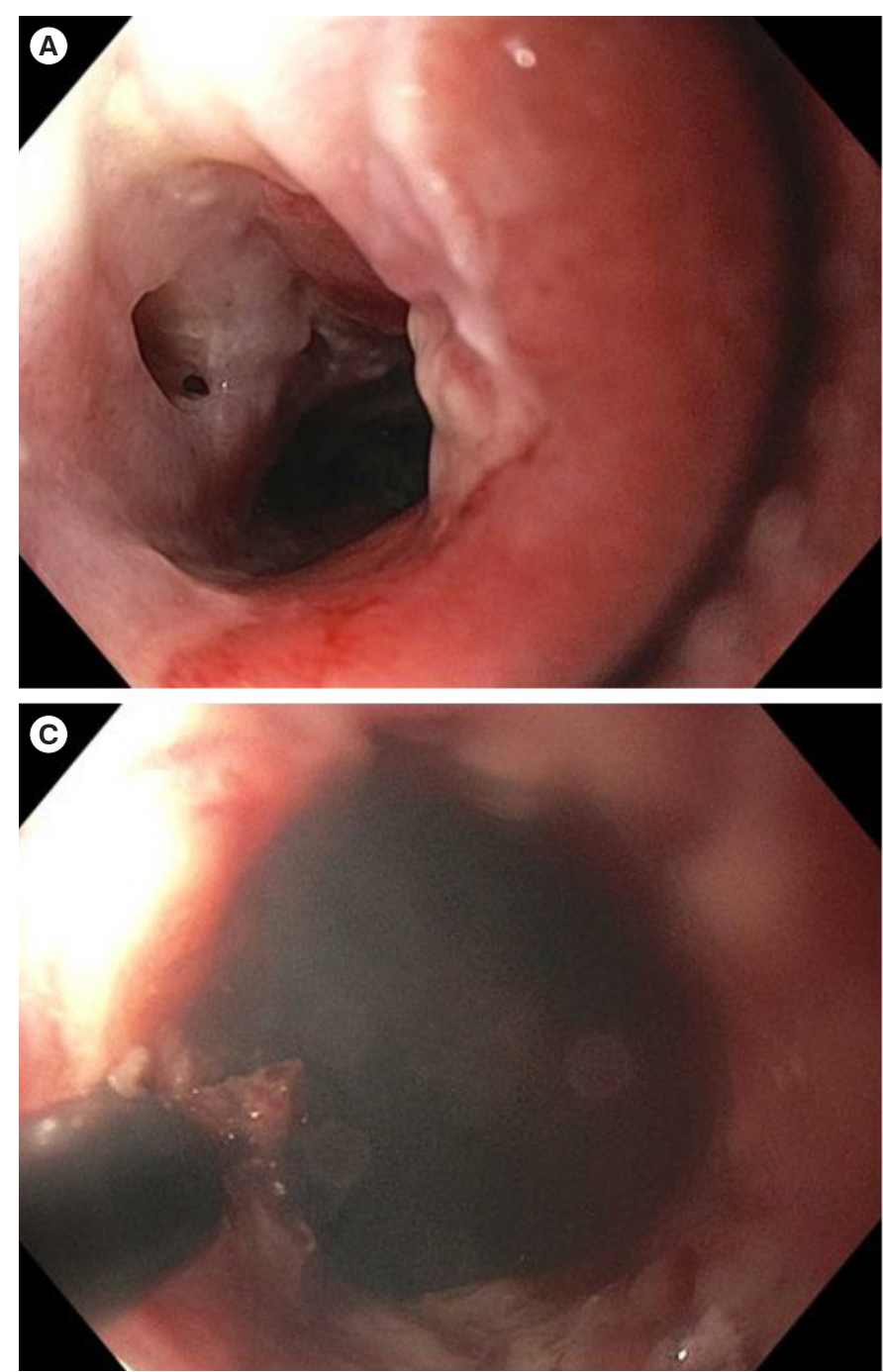

\section{ENDOSCOPIC STRICTUROTOMY AND STRICTUREPLASTY}

The requirement of repeat EBD or surgical intervention in CD strictures has prompted the development of endoscopic electroincision in the treatment of refractory CD-associated stricture. The same techniques have been used to treat esophageal, pyloric, and duodenum papillary strictures. Its use in CD strictures is a natural extension.

\section{Techniques}

Endoscopic electroincision provides for a more precise approach in treating a stricture, in contrast to the blunt force mechanism in an EBD. To date, endoscopic electroincision
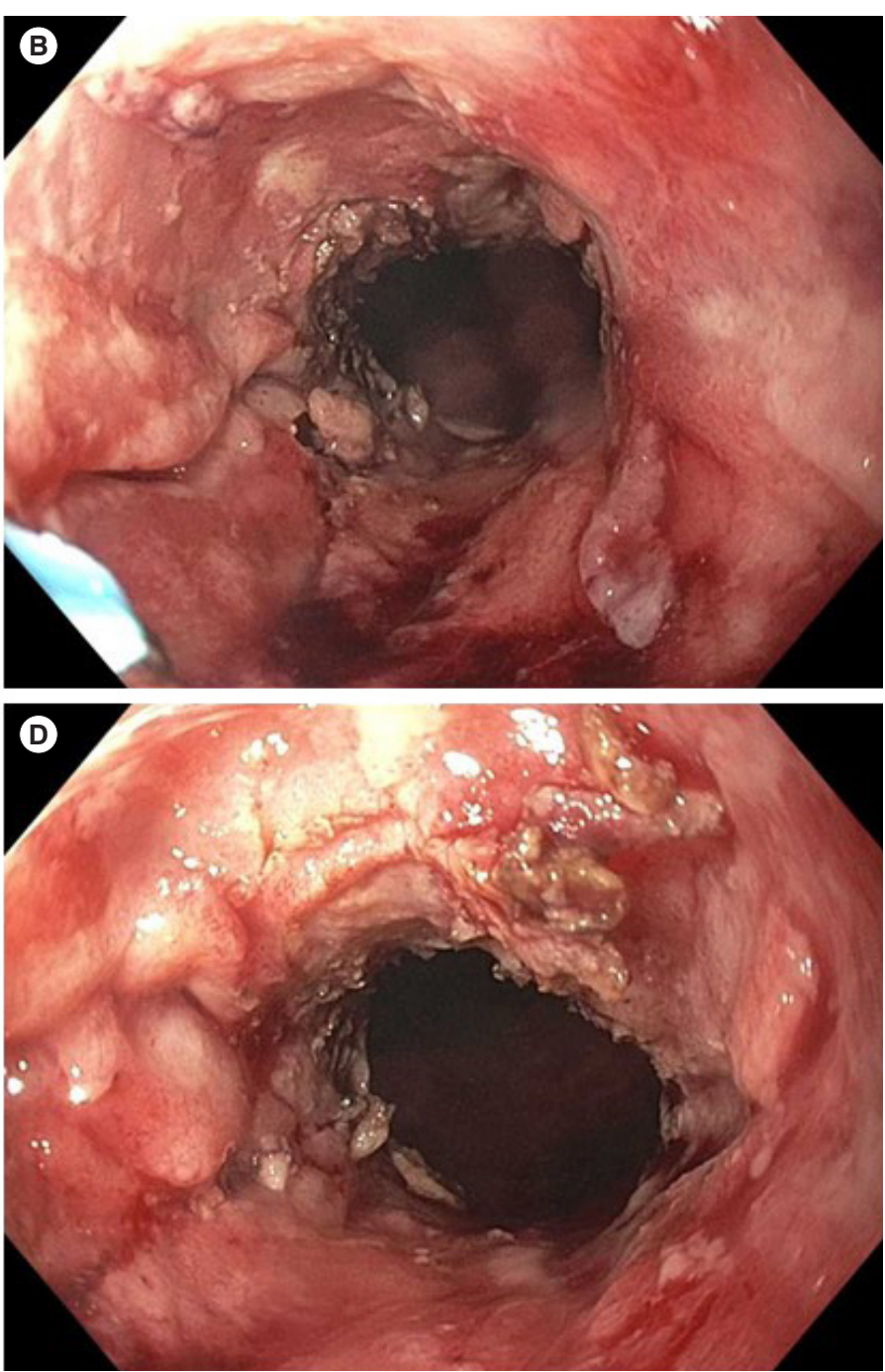

Fig. 3. Endoscopic stricturotomy of a long anorectal stricture in CD. (A) The 6-cm long tight ulcerated stricture resulting from the disease and previous repeated endoscopic balloon and bougie dilations. (B) Stricturotomy with a needle knife. (C) Stricturotomy with an insulated-tip knife. (D) Posttreatment appearance of the stricture. 

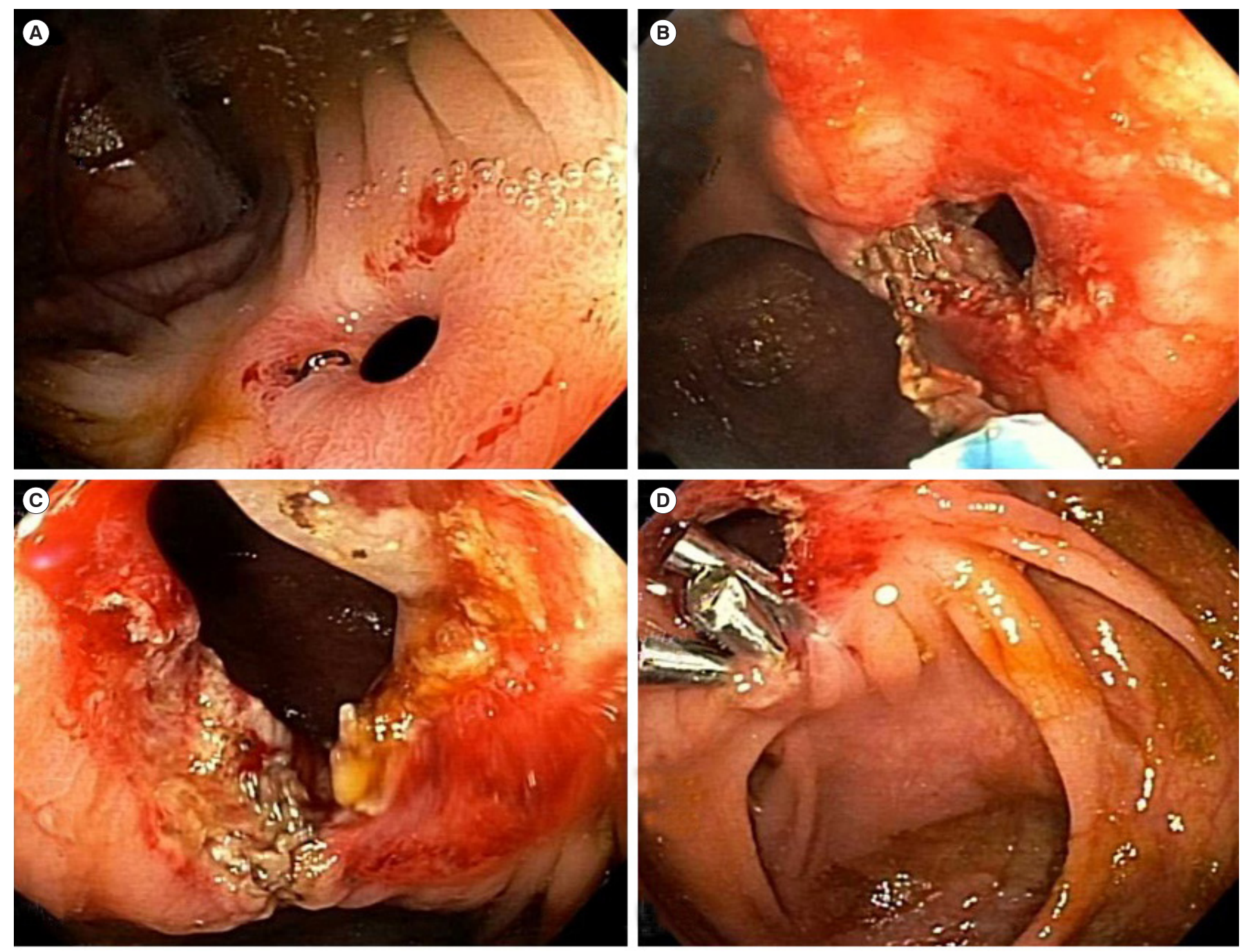

Fig. 4. Endoscopic strictureplasty of an ileocolonic anastomotic stricture in CD. (A) The short, ulcerated stricture with dislodged staples at the anastomosis. $(B, C)$ Endoscopic electroincision with a needle knife. (D) Placement of endoclips to the incised stricture as spacers.

consists of 2 modalities, ESt and ESTx The difference between electroincision and EBD is that electroincision is delivered with a precision-cut in terms of location and depth (Figs 3, 4). Another advantage of using electroincision when performed in the anorectum is the reduction of the risk of trauma to the anterior wall of the distal anorectum and anal sphincter. If an EBD is used, trauma could occur in these regions due to the force of the balloon. Strictures in the esophagus, pylorus, duodenum, distal small bowel, colon, and anorectum, ileostomy, strictureplasty site, and ileal pouch can be treated with ESTx or ESt.

\section{Short and Long-term Efficacy in Case Series}

The efficacy of ESTx and Est in case series has been documented extensively. In one study, ESt was confirmed to be fea- sible in treating strictures in patients in IBD (including CD) as there was a $15.3 \%$ subsequent surgery rate and a $0.4 \%$ perforation rate. ${ }^{18}$ In addition, $9.8 \%$ of patients treated in a study with ESt eventually underwent salvage surgery. Nonetheless, ESt or ESTx are more effective approaches to either reduce the probability of surgery or avoid surgery altogether than EBD.

\section{Comparison of Efficacy of Endoscopic Electroincision and EBD}

The efficacy and safety of endoscopic electroincision have been compared with EBD and surgical resection in the treatment of primary or anastomotic strictures of CD. Lan and Shen ${ }^{19}$ reported long-term outcomes after ESt or ESTx versus EBD for anastomotic strictures in CD. For 185 patients, 21 were treated with ES and 164 with EBD. Immediate technical 
success was achieved in $100 \%$ of patients treated with ES and 89.5\% of patients with EBD. Symptomatic and endoscopic improvement rates were higher in those treated with ESt or ESTx than EBD. Subsequent surgery was needed in 2 (9.5\%) patients with ESTx and 55 (33.5\%) with EBD, during a median of 0.8 year and 4.0 years, respectively. Five procedure-associated perforations (1.1\% per procedure) occurred in the EBD group and none in the ESTx group. In contrast, 4 procedure-associated, transfusion-required bleeding ( $8.8 \%$ per procedure) occurred in the ESTx group and none in the EBD group. The authors concluded that ESTx appears to be more effective in CD with an anastomotic stricture than EBD.

\section{Comparison of Efficacy of Endoscopic Electroincision and Surgical Resection}

Endoscopic electroincision is a promising alternative to surgery as well. A recent study comparing ESt $(n=35)$ and surgical $(n=147)$ re-resection found that of its patients who underwent ESt, 3 out of 48 of patients (6.2\%) had posttreatment complications. In contrast, patients with surgical re-resection had a rate of $30.5 \%$ of postoperative complications. During a follow-up period of 1.1 and 2.1 years in the stricturotomy and surgical groups, respectively, disease-related hospitalization was found to be more common in the surgical group. ${ }^{20}$ Thus, endoscopic electroincision can reduce the posttreatment complication rate and be used as the first-line plausible treatment to CD-related strictures.

There are no published data on the comparison of the outcomes between endoscopic electroincision and surgical strictureplasty in the treatment of CD strictures.

\section{Adverse Events Associated with Endoscopic Electroincision}

Endoscopic electroincision has a lower risk for perforation but a higher risk for bleeding than EBD. The bleeding typically occurs within 4 days after the procedure, resulting from ulcer surface created by the electroincision. A low setting of electric cutting of the knife and administration of $50 \%$ glucose may help reduce the risk. The patients should be closely monitored.

\section{ENDOSCOPIC STENTING}

Self-expandable metallic stents (SEMS) have been used for the treatment of long or refractory (to EBD or surgery) strictures. The use of biodegradable stents has even been attempted. ${ }^{21}$

\section{Techniques}

A method that has also been explored in the treatment of strictures. The limited data are in the form of case reports or small case series for ES in CD strictures. ${ }^{1,14,22}$ Recorded data has suggested that the use of metal stents is a practice that can be used in the treatment of strictures in CD. The reported success rate was as high as $92 \%{ }^{1,23}$ There is no consensus on the size and duration of the stent.

\section{Outcomes}

According to the limited published data, a short-term success rate of SEMS is high. In one study, 16 out of 17 patients were placed correctly, and the treatment was successful in 11 of the 17 patients (64.7\%). ${ }^{19}$ After therapy, the recurrence rate of structuring was $43.7 \%$ in the patients. Overall, the efficacy in the study (64.7\%) was greater than the efficacy obtained using EBD in high-risk patients (58\%). ${ }^{19}$ Thus, ES can be a viable option in highly selected patients. The main safety concerns are stent migration, perforation, and abscess. The authors find that the new lumen-apposing metal stent is particularly useful in the treatment of refractory, short side-to-side ileocolonic anastomosis (Fig. 5).

\section{SELECTION OF ENDOSCOPIC THERAPY}

The long-term efficacy of endoscopic therapy in terms of durability in controlling the stricture as well as avoiding surgery is an important factor to consider when choosing endoscopy for stricture management. The efficacy of EBD in the treatment of CD strictures has been compared with the surgical approach. EBD provides the safest way to treat strictures. However, compared to surgery, EBD is not as effective in treating CD-related anastomotic strictures. Although in anastomotic and primary stricture treatment EST, or surgery, may contain better results, EBD is a promising endoscopic alternative to surgery for patients who may not be able to undergo surgery.

Comparing EBD versus surgery for anastomotic stricture in CD following ileocolonic resection, EBD delayed surgery by an average time of 6.45 years. ${ }^{10}$ The long-term efficacy of endoscopic therapy can help deter the time for surgery when managing strictures. The deferred duration for the subsequent surgery may be shorter in primary strictures. ${ }^{13}$ Therefore, it is important to select proper patients for endoscopic vs. surgical approaches. Our group demonstrated that the frequency of postoperative complications was higher in those undergoing 

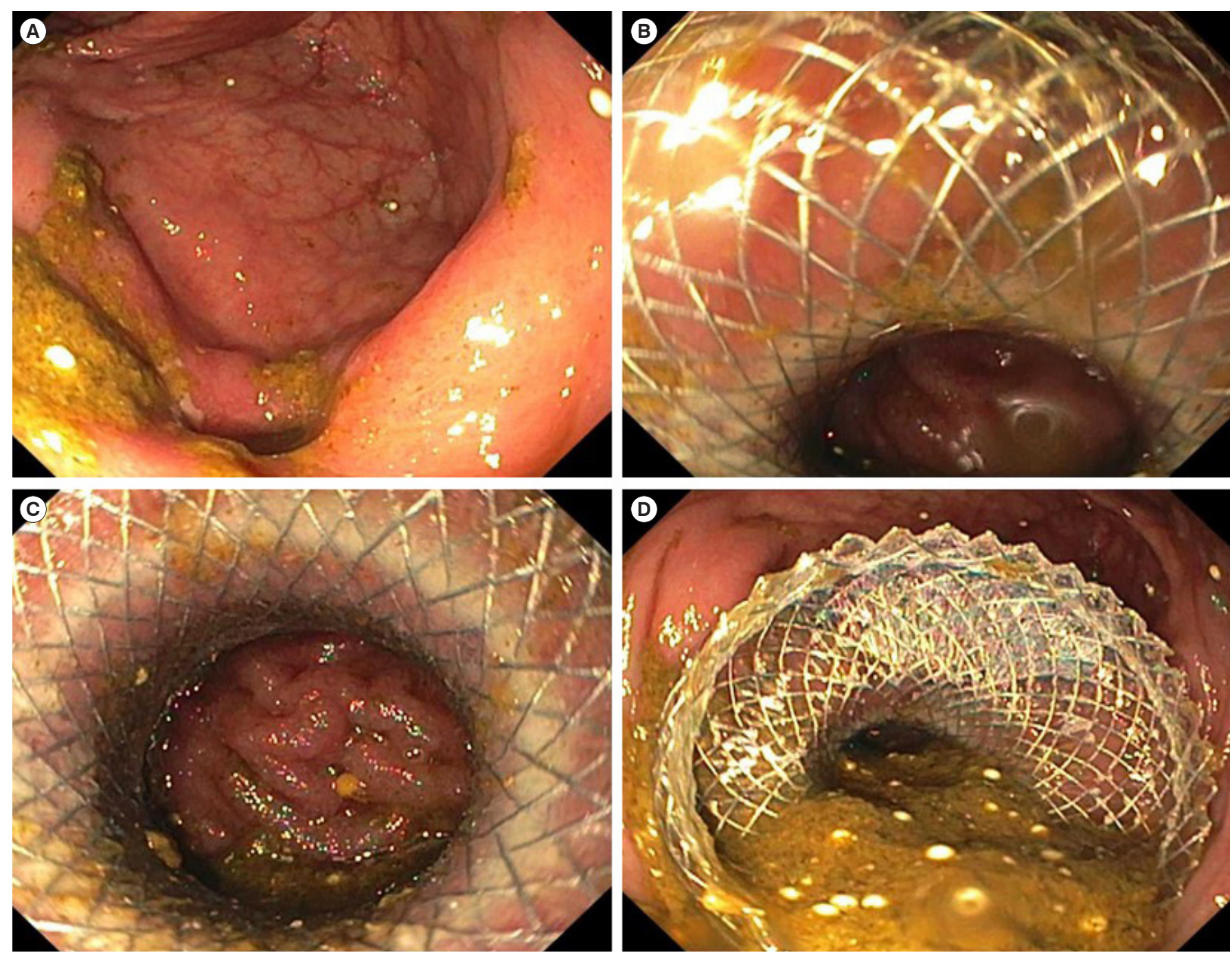

Fig. 5. Endoscopic stenting of a short ileocolonic anastomotic stricture in CD. (A) The tight, short anastomosis stricture. (B-D) Placement of a $22 \times 10 \mathrm{~mm}$ lumen-opposing metal stent.

EBD for ileocolonic anastomosis strictures then requiring salvage surgery due to EBD failure than those having upfront surgery without trying EBD. ${ }^{8}$

Our group has developed a nomogram showing a group of patients with anastomotic strictures in $\mathrm{CD}$ who would have a poor response to EBD therapy. The parameters listed in the nomogram included symptomatic disease, a longer time interval from last surgery, and radiographic proximal bowel dilation. ${ }^{4}$ Patients with those risk factors may benefit from upfront surgery. In contrast, those without these factors may be treated with EBD first. With emerging data, similar nomograms can be developed for endoscopic electroincision or ES in the treatment of primary as well as anastomotic strictures.

\section{CONCLUSION}

Endoscopic therapy is an effective approach to treat strictures in CD. Implementing endoscopic therapy for CD-related strictures periodically may reduce the need for surgery. With better endoscopic management for strictures, the number of surgeries can be decreased over for years. This would lessen the risk of complications for a patient with CD. Endoscopic techniques are effective therapy a middle ground between medical and surgical therapy. It is more effective than medicine and less invasive than surgery makes it an appealing method in treating strictures. Thus, endoscopy can be complementary to medical therapy and surgery and with periodic endoscopic therapy the number of surgeries in patient can be reduced. 


\section{FINANCIAL SUPPORT}

The authors received no financial support for the research, authorship, and/or publication of this article.

\section{CONFLICT OF INTEREST}

No potential conflict of interest relevant to this article was reported.

\section{AUTHOR CONTRIBUTION}

Draft of the manuscript: Pokala A. Concept and revision: Shen B. Approval of final manuscript: all authors.

\section{ORCID}

Pokala A

Shen B

https://orcid.org/0000-0002-3770-7144

https://orcid.org/0000-0002-7229-4840

\section{REFERENCES}

1. East JE, Brooker JC, Rutter MD, Saunders BP. A pilot study of intrastricture steroid versus placebo injection after balloon dilatation of Crohn's strictures. Clin Gastroenterol Hepatol 2007;5: 1065-1069.

2. Di Nardo G, Oliva S, Passariello M, et al. Intralesional steroid injection after endoscopic balloon dilation in pediatric Crohn's disease with stricture: a prospective, randomized, doubleblind, controlled trial. Gastrointest Endosc 2010;72:1201-1208.

3. Li Y, Stocchi L, Shen B, Liu X, Remzi FH. Salvage surgery after failure of endoscopic balloon dilatation versus surgery first for ileocolonic anastomotic stricture due to recurrent Crohn's disease. Br J Surg 2015;102:1418-1425.

4. Shivashankar R, Edakkanambeth Varayil J, Scott Harmsen W, et al. Outcomes of endoscopic therapy for luminal strictures in Crohn's disease. Inflamm Bowel Dis 2018;24:1575-1581.

5. Scimeca D, Mocciaro F, Cottone M, et al. Efficacy and safety of endoscopic balloon dilation of symptomatic intestinal Crohn's disease strictures. Dig Liver Dis 2011;43:121-125.

6. Gustavsson A, Magnuson A, Blomberg B, Andersson M, Halfvarson J, Tysk C. Endoscopic dilation is an efficacious and safe treatment of intestinal strictures in Crohn's disease. Aliment Pharmacol Ther 2012;36:151-158.

7. Mueller T, Rieder B, Bechtner G, Pfeiffer A. The response of Crohn's strictures to endoscopic balloon dilation. Aliment
Pharmacol Ther 2010;31:634-639.

8. Lee HW, Park SJ, Jeon SR, et al. Long-term outcomes of endoscopic balloon dilation for benign strictures in patients with inflammatory bowel disease. Gut Liver 2018;12:530-536.

9. Lian L, Stocchi L, Shen B, et al. Prediction of need for surgery after endoscopic balloon dilation of ileocolic anastomotic stricture in patients with Crohn's disease. Dis Colon Rectum 2015;58:423-430.

10. Atreja A, Aggarwal A, Dwivedi S, et al. Safety and efficacy of endoscopic dilation for primary and anastomotic Crohn's disease strictures. J Crohns Colitis 2014;8:392-400.

11. Chen M, Shen B. Comparable short- and long-term outcomes of colonoscopic balloon dilation of Crohn's disease and benign non-Crohn's disease strictures. Inflamm Bowel Dis 2014;20: 1739-1746.

12. Lian L, Stocchi L, Remzi FH, Shen B. Comparison of endoscopic dilation vs surgery for anastomotic stricture in patients with Crohn's disease following ileocolonic resection. Clin Gastroenterol Hepatol 2017;15:1226-1231.

13. Morar PS, Faiz O, Warusavitarne J, et al. Systematic review with meta-analysis: endoscopic balloon dilatation for Crohn's disease strictures. Aliment Pharmacol Ther 2015;42:11371148.

14. Axelrad JE, Lichtiger S, Sethi A. Treatment of Crohn's disease anastomotic stricture with a lumen-apposing metal stent. Clin Gastroenterol Hepatol 2018;16:A25-A26.

15. Bettenworth D, Gustavsson A, Atreja A, et al. A pooled analysis of efficacy, safety, and long-term outcome of endoscopic balloon dilation therapy for patients with stricturing Crohn's disease. Inflamm Bowel Dis 2017;23:133-142.

16. Lan N, Stocchi L, Ashburn JH, et al. Outcomes of endoscopic balloon dilation vs surgical resection for primary ileocolic strictures in patients with Crohn's disease. Clin Gastroenterol Hepatol 2018;16:1260-1267.

17. Klag T, Wehkamp J, Goetz M. Endoscopic balloon dilation for Crohn's disease-associated strictures. Clin Endosc 2017;50:429436.

18. Lan N, Shen B. Endoscopic stricturotomy with needle knife in the treatment of strictures from inflammatory bowel disease. Inflamm Bowel Dis 2017;23:502-513.

19. Lan N, Shen B. Endoscopic stricturotomy versus balloon dilation in the treatment of anastomotic strictures in Crohn's disease. Inflamm Bowel Dis 2018;24:897-907.

20. Lan N, Shen B. Endoscopic stricturotomy vs surgical re-resection in the treatment of anastomotic strictures in Crohn's disease. Gastrointest Endosc 2018;87:AB237-AB238. 
21. Karstensen JG, Christensen KR, Brynskov J, Rønholt C, Vilmann P, Hendel J. Biodegradable stents for the treatment of bowel strictures in Crohn's disease: technical results and challenges. Endosc Int Open 2016;4:E296-E300.

22. El Ouali S, Kessler H, Shen B. Self-expandable metal stent in the treatment of refractory long pouch inlet stricture. Inflamm Bowel Dis 2019;25:e13-e14.

23. Loras C, Pérez-Roldan F, Gornals JB, et al. Endoscopic treatment with self-expanding metal stents for Crohn's disease strictures. Aliment Pharmacol Ther 2012;36:833-839. 